\title{
ACHONDROPLASIA- A RARE CASE REPORT
}

Sabita Pulavarthi' ${ }^{1}$ Suba Ananthi Kumarasamy², Umamageswari Amirthalingam³

${ }_{1}^{1}$ Associate Professor, Department of Obstetrics and Gynaecology, Indira Gandhi Medical College and Research Institute, Puducherry, India.

${ }^{2}$ Associate Professor, Department of Anatomy, Indira Gandhi Medical College and Research Institute, Puducherry, India.

${ }_{3}^{3}$ Associate Professor, Department of Radiodiagnosis, Sri Manakula Vinayagar Medical College and Hospital, Puducherry, India.

HOW TO CITE THIS ARTICLE: Pulavarthi S, Kumarasamy SA, Amirthalingam U. Achondroplasia- a rare case report. J. Evolution Med. Dent. Sci. 2019;8(18):1517-1518, DOI: 10.14260/jemds/2019/336

\section{PRESENTATION OF CASE}

A 29-year-old female patient, G2P1L1 of 32 weeks' gestation, who has not attended any antenatal clinic, presented with premature rupture of membrane, to the Department of Obstetrics and Gynaecology, delivered a still born female baby with bilateral short upper and lower limbs, proptosis, depressed nasal bridge, short neck, narrow thoracic cage, protuberant abdomen and redundant skin folds (Figure 1). There was no significant family history or consanguineous marriage. No history of any infection and drug intake during the gestation period. She had delivered a normal male baby in the same institute in 2013.

\section{DIFFERENTIAL DIAGNOSIS}

- Thanatophoric Dysplasia.

- Homozygous Achondroplasia.

- Osteogenesis Imperfecta.

- Achondrogenesis.

\section{CLINICAL DIAGNOSIS}

The baby was diagnosed as a case of Achondrogenesis (AG) with clinical presentation of micromelia, short trunk and protuberant abdomen. Postnatal X-ray and CT Scan was done to visualize the morphology of the limb bones and other associated anomalies. Normal ossifications of cranial bones were noted. Both upper and lower limb bones were short. Femur was very short, broad with metaphyseal cupping, platyspondyly vertebral bodies, abnormal scapula with short ribs were observed. Absence of ossification of sacrum, ischia and pubis was observed (Figure 2).

\section{PATHOLOGICAL DISCUSSION}

Histopathologically, the physeal growth zone in both AG I and II shows severe retardation and disorganisation. The resting cartilage of AG IA has large PAS-positive diastase-resistant spherical or oval chondrocytic inclusions in membrane bound vacuoles.1,2 But AG IB has unusual perichondrocytic collagen rings which are strongly reactive with silver methenamine, trichrome or toluidine blue stain with absent intervening matrix, due to decrease of type II collagen. ${ }^{3}$

'Financial or Other Competing Interest': None.

Submission 14-03-2019, Peer Review 19-04-2019,

Acceptance 26-04-2019, Published 06-05-2019.

Corresponding Author:

Dr. Suba Ananthi Kumarasamy,

Associate Professor,

Department of Anatomy,

Indira Gandhi Medical College and Research Institute,

Kathirakamam, Pondicherry-605009, India.

E-mail: subasara@yahoo.com

DOI: $10.14260 /$ jemds $/ 2019 / 336$

\section{(c) $(i) \subseteq$}

The histopathological changes of the resting cartilage are characteristic with significant deficiency of matrix and markedly enlarged lacunae. Cartilage canals are markedly enlarged, stellate in shape and fibrotic. Immunohistochemical studies reveal the predominant collagen of cartilage is type I rather than type II which is normally found, confirming that it is a disorder of type II collagen biosynthesis. ${ }^{4}$

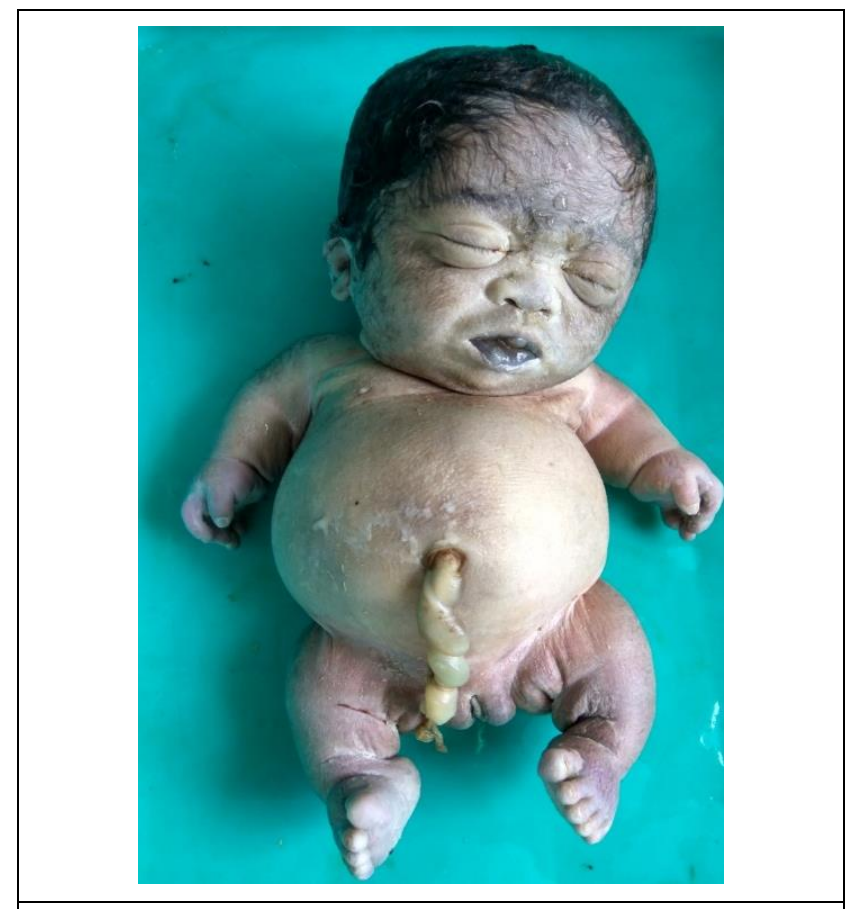

Figure 1. Still Born Baby with Micromelia, Short Trunk and Protuberant Abdomen

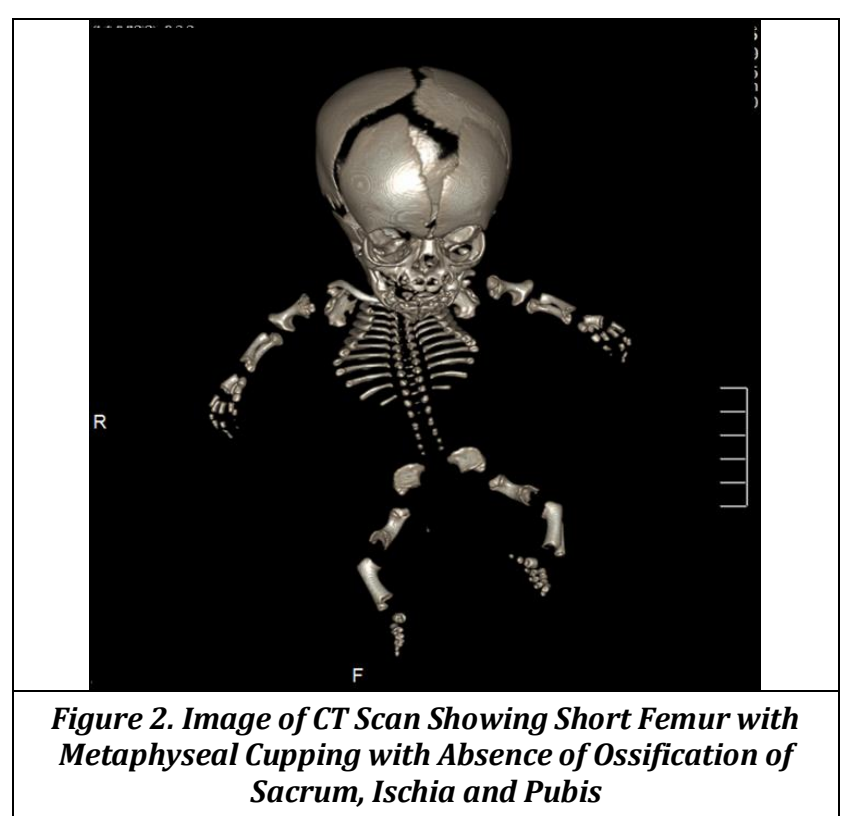




\section{DISCUSSION}

Skeletal Dysplasia is a heterogenous group of genetic conditions characterized by abnormal shape, growth or integrity of bones with different forms of inheritance and presentation. Achondrogenesis (AG) is a severe lethal form of short-trunk osteochondrodysplasia with the prevalence of 0.1 per 10,000 among the 1.1 per 10,000 births of skeletal dysplastic neonates. ${ }^{5} \mathrm{AG}$ is divided into 2 types. Type I which is an autosomal recessive condition and Type II an autosomal dominant condition. Type I is of two subtypes namely Type IA called as Houston Harris type and Type IB as Fraccaro Dysplasia. AG Type II is also called as Langer Saldino Dysplasia. ${ }^{6}$ Clinical presentation of both AGI and II is similar with extremely short trunk and extremities. Cardiac anomalies like patent ductus arteriosus, atrial septal defect and ventricular defect are noted. Hydropic appearance and polyhydramnios are present. 7

The difference between AG IA and IB is deficiency of cranial bone ossification and thin ribs with multiple fractures is observed in IA whereas IB has no rib fractures and has adequate cranial bone ossification. Spike-like metaphyseal spurs in the extremely short limb bones and absence of ossification in ischia, pubis and vertebrae are the characteristic radiographic findings of AG I. ${ }^{1}$ AG IB is caused due to mutations of DTDST (Diastrophic dysplasia Sulfate transporter) gene located on chromosome 5q. AG II is a type II Collagenopathy, caused by mutations in COL2A1 gene located on chromosome 12q3.1-13.38. AG IA can be excluded by absence of rib fracture and well ossified cranial bones. AG IB can be excluded by the absence of metaphyseal spikes and presence of metaphyseal cupping. Affected babies are often stillborn or perish shortly after they are born. Die of respiratory failure owing to hypoplastic lung.

\section{FINAL DIAGNOSIS}

Achondrogenesis is a Lethal bone dysplasia, micromelic dwarfism caused by allelic mutations of the COL2A1 gene located on chromosome 12q3.1-13.3. Prenatal diagnosis is possible with ultrasonographic confirmation as early as 12 weeks of gestation ${ }^{9}$ and hence the foetus can be aborted at an early gestational age. Chromosome analysis will reveal the molecular defects in chondrodysplasias.

\section{REFERENCES}

[1] van der Harten HJ, Brons JT, Dijkstra PF, et al. Achondrogenesis-hypochondrogenesis: the spectrum of chondrogenesis imperfect. A radiological, ultrasonographic and histopathologic study of 23 cases. Paediatr Pathol 1988;8(6):571-97.

[2] Yang SS, Heidelberger KP, Bernstein J. Intracytoplasmic inclusion bodies in the chondrocytes of type I lethal achondrogenesis. Hum Pathol 1976;7(6):667-73.

[3] Freisinger P, Stanescu V, Jacob B. Achondrogenesis type IB (Fraccaro): study of collagen in the tissue and in chondrocytes cultured in agarose. Am J Med Genet 1994;49(4):439-46.

[4] Horton WA, Machado MA, Chou JW. Achondrogenesis type II, abnormalities of extracellular matrix. Paedtr Res. 1987;22(3):324-9.

[5] Connor JM, Connor RA, Sweet EM, et al. Lethal neonatal chondrodysplasias in the West of Scotland 1970-1983 with the description of a thanatophoric, dysplasialike, autosomal recessive disorder, Glasgow variant. Am J Med Genet 1985;22(2):243-53.

[6] Borochowitz Z, Lachman R, Adomian GE, et al. Achondrogenesis type I: delineation of further heterogeneity and identification of two distinct subgroups. J Paediatr 1988;112(1):23-31.

[7] Gilbert-Barness E. Potter's pathology of the fetus, infant and child. $2^{\text {nd }}$ edn. Philadelphia: Mosby Elsevier 2007:1843-8.

[8] Mortier GR, Wilkin DJ, Wilcox WR, et al. A radiologic, morphologic, biochemical and molecular analysis of a case of achondrogenesis type II resulting from substitution of a glycine residue (Gly691-->Arg) in the type II collagen trimer. Humen Mol Genet 1995;4(2):285-8.

[9] Soothill PW, Vuthiwong C, Rees H. Achondrogenesis type 2 diagnosed by transvaginal ultrasound at 12 weeks gestation. Prenat Diagn 1993;13(6):523-38. 